\title{
Genetic effect of interleukin-1 beta (C-511T) polymorphism on the structural covariance network and white matter integrity in Alzheimer's disease
}

Chi-Wei Huang ${ }^{1 \dagger}$, Shih-Wei Hsu ${ }^{2 \dagger}$, Shih-Jen Tsai, ${ }^{3,4}$, Nai-Ching Chen ${ }^{1}$, Mu-En Liu ${ }^{3}$, Chen-Chang Lee², Shu-Hua Huang ${ }^{5}$, Weng-Neng Chang ${ }^{1}$, Ya-Ting Chang ${ }^{1}$, Wan-Chen Tsai ${ }^{1}$ and Chiung-Chih Chang ${ }^{1 *}$

\begin{abstract}
Background: Inflammatory processes play a pivotal role in the degenerative process of Alzheimer's disease. In humans, a biallelic (C/T) polymorphism in the promoter region (position-511) (rs16944) of the interleukin-1 beta gene has been significantly associated with differences in the secretory capacity of interleukin- 1 beta. In this study, we investigated whether this functional polymorphism mediates the brain networks in patients with Alzheimer's disease.

Methods: We enrolled a total of 135 patients with Alzheimer's disease (65 males, 70 females), and investigated their gray matter structural covariance networks using 3D T1 magnetic resonance imaging and their white matter macro-structural integrities using fractional anisotropy. The patients were classified into two genotype groups: C-carriers $(n=108)$ and $\Pi$-carriers $(n=27)$, and the structural covariance networks were constructed using seed-based analysis focusing on the default mode network medial temporal or dorsal medial subsystem, salience network and executive control network. Neurobehavioral scores were used as the major outcome factors for clinical correlations.

Results: There were no differences between the two genotype groups in the cognitive test scores, seed, or peak cluster volumes and white matter fractional anisotropy. The covariance strength showing C-carriers $>\Pi$-carriers was the entorhinal-cingulum axis. There were two peak clusters (Brodmann 6 and 10) in the salience network and four peak clusters (superior prefrontal, precentral, fusiform, and temporal) in the executive control network that showed $\mathrm{C}$-carriers $<\Pi$-carriers in covariance strength. The salience network and executive control network peak clusters in the $\Pi$ group and the default mode network peak clusters in the C-carriers strongly predicted the cognitive test scores.

Conclusions: Interleukin-1 beta C-511 T polymorphism modulates the structural covariance strength on the anterior brain network and entorhinal-interconnected network which were independent of the white matter tract integrity. Depending on the specific C-511 T genotype, different network clusters could predict the cognitive tests.
\end{abstract}

Keywords: Alzheimer's disease, Anatomical structural covariance, Interleukin-1 beta polymorphism, Salience network, Executive control network

\footnotetext{
*Correspondence: neur099@adm.cgmh.org.tw

†'Equal contributors

'Department of Neurology, Cognition and Aging Center, Kaohsiung Chang

Gung Memorial Hospital, Chang Gung University College of Medicine, \#123,

Ta-Pei Road, Niaosung, Kaohsiung County 833, Taiwan

Full list of author information is available at the end of the article
} 


\section{Background}

The neuropathology of Alzheimer's disease (AD) involves a profound innate immune response and production of inflammatory cytokines [1]. Whether or not inflammatory processes represent a causal component of $\mathrm{AD}$ or are simply a consequence of neurodegeneration is still under debate. However, it is generally accepted that inflammatory cascades [2] together with neurofibrillary tangles [3] and degenerative neuroimaging biomarkers [4] are more strongly associated with cognitive declines in patients with AD. Many inflammatory mediators have been identified in the brains of patients with AD. Variations in inflammatory-related genes have been extensively investigated [5-8], and the expression of interleukin-1 (IL-1) beta has been shown to have clinical relevance. IL-1 beta, produced in the glial cells and neurons, has been reported to have a higher density in the hippocampus in response to stress of injury [9]. In addition, in an Alzheimer's mouse model, IL-1 betarelated inflammatory responses surprisingly reduced amyloid beta deposition [10] but paradoxically enhanced tau pathology [11].

A large number of functional polymorphisms in the promoter regions of pro- and anti-inflammatory genes have been associated with different levels of mediators that have an overall effect on the strength of inflammatory responses [12]. The human interleukin-1 beta gene (IL1B) is located on chromosome 2q14. A biallelic (C/T) polymorphism in the promoter region (position-511) (rs16944) of the IL-1 beta gene has been significantly associated with IL-1 beta secretory capacity after lipopolysaccharide-stimulation that $\mathrm{T}$ homozygous individuals secreted significantly more IL-1 beta than CC and CT individuals [13]. In Taiwan, the -511 TT genotype has also been associated with an increased risk of AD [14]. The substantial increase in the expression of the IL-1 beta gene during long-term potentiation of synaptic transmission suggests its role in synaptic function [15]; however, blocking of IL-1 beta in the hippocampus has been reported to produce significant memory impairment compared with vehicle-treated rats [16].

Both deep and periventricular white matter hyperintensities (WMHs) have been reported to be significantly associated with $\mathrm{AD}$ degeneration process in both crosssectional and longitudinal studies [17-19]. The presence of WMHs in AD may reflect multiple physiological and pathological changes such as breakdown of the bloodbrain barrier [20], impaired cerebral auto-regulation [21], vasculopathies, and inflammation [22, 23]. In healthy adults, homozygotes for the IL-1 beta $-511 \mathrm{~T}$ allele have been associated with increased inflammatory responses and larger WMHs than the other two genotypic combinations [24]. The $-511 \mathrm{~T}$ homozygotes are also associated with a higher risk of ischemic stroke, suggesting a role in large [25] or small vessel pathology [26]. These observations make the IL-1 beta C-511 T genetic variant a plausible candidate to evaluate the genetic effect on WMH proliferation. Data on the C-511 T with regards to WMH load and gray matter (GM) degeneration in AD are still lacking.

The application of structural covariance networks (SCNs) has been supported by recent research in that highly related regions may show covariance in morphometric characteristics. SCN patterns have been shown to be associated with structural or functional connectivity while the structural covariance strength often reflects how close two interconnected hubs interact [27]. Meanwhile, biological factors such as genetic variations, developmental, degenerative processes or the WMH loads [24] have been shown to modulate the patterns of SCNs [27]. Three SCNs have been reported to be relevant to $\mathrm{AD}$, the so called default mode network (DMN) [28-30], salience network (SN) [31], and executive control network (ECN) [32, 33]. A recent report suggested that the DMN may be comprised of multiple, spatially dissociated but interactive components, of which two subsystems are particularly relevant: the "medial temporal lobe subsystem", and the "dorsal medial prefrontal cortex subsystem" (or the midline core subsystem) [34].

An association between the IL- 1 beta $-511 \mathrm{~T}$ allele and AD has been reported [14], however the mechanism by which IL-1 beta functional polymorphisms affect the brain networks in patients with $\mathrm{AD}$ has yet to be explored. Recent neuroscience studies have supported that cognitive function is highly reflective of the architecture of the neuronal network scaffold [35]. As the potential mechanisms of genetic-based neurobiology are still under investigation [36-39], the exploration of IL-1 beta functional polymorphism may address how genetic variations may affect the organization of the GM and white matter (WM) integrities. The neuroimaging biomarkers of SCN and WMH spatial distribution can be used to test the influence of the genotype groups with regards to inflammatory processes on disease-related degeneration. In this study, we hypothesized that the IL-1 beta C$511 \mathrm{~T}$ functional polymorphism may modulate largescale structural covariance patterns and WMHs in patients with $\mathrm{AD}$, and that these alterations may consequently determine neurobehavioral performance.

\section{Methods}

The patients were treated at the Cognition and Aging Center, Department of General Neurology, Kaohsiung Chang Gung Memorial Hospital. A total of 135 AD subjects (65 males, 70 females) were included after the consensus of a panel composed of neurologists, neuropsychologists, neuroradiologists, and experts in nuclear medicine [23]. AD was diagnosed according to the 
International Working Group criteria [40], with a clinical diagnosis of typical AD encompassing both prodromal and dementia phases. Amnestic syndrome of the hippocampal type was characterized by a low free recall that was not normalized by cueing [41]. All of the patients had a clinical dementia rating scores ranges from 0.5 to 2 , and all of the patients were in a stable condition under treatment with acetylcholine esterase inhibitors from the time of diagnosis. The exclusion criteria were a past history of clinical stroke, a modified Hachinski ischemic score $>4$ [42] and depression.

\section{Study working scheme}

Based on the study rationale, the patients were classified into two genotype groups based on the functional polymorphism: C carrier $(\mathrm{CC}+\mathrm{CT}, n=108)$, and TT homozygotes $(n=27)$. The working scheme was as follows. First, four SCN were established by seed-based correlation analysis. Differences in each seed regional volume and SCN peak cluster volume were compared between the two genotype groups. Meanwhile, neuroimaging biomarkers used to assess the micro-structural of the WM integrities were derived from the diffusion tensor imaging, compared between groups and correlated with cognitive test scores. Finally, to evaluate the genetic effects on SCN clusters, the covariance strength showing significant genotype interactions (i.e., $\mathrm{T}$ homozygotes $>\mathrm{C}$-carriers or $\mathrm{T}$ homozygotes $<\mathrm{C}$-carriers) were modeled. The volumes of the peak clusters showing genotype effect was correlated with cognitive test scores to evaluate the clinical significance.

\section{Clinical and neurobehavioral assessments}

After enrolment, demographic data of each patient were recorded. A trained neuro-psychologist administered the neurobehavior tests. The Mini-Mental State Examination (MMSE) [43] and the Cognitive Abilities Screening Instrument (CASI) [44] total scores were used as a global assessment of cognitive function. Attention, verbal fluency, abstract thinking, and mental manipulation subdomain scores of the CASI were used to assess executive function test (EFT) [22], while the non-executive domains included orientation, short- and long-term memory, language ability, and drawing.

\section{Genotyping}

Genomic DNA was extracted from blood samples using a commercial kit (Qiagen, Gentra Puregene Blood Kit), followed by genotyping for C-511 $\mathrm{T}$ polymorphisms of the IL-1 beta gene using the polymerase chain reaction (PCR)-restriction fragment length polymorphism method [45]. Genotyping was conducted with the operator blinded to the clinical data. The apolipoprotein $\mathrm{E}$ genotype was also determined using a PCR-restriction fragment length polymorphism assay and restriction enzyme HhaI [46]. Apolipoprotein E4 carriers were defined as those with one or two E4 alleles [23].

\section{Cerebrovascular risk confounders}

Factors such as oxidative stress, deregulated metabolic factors and an elevated blood sugar level are related to greater WMHs loads in AD [23]. Therefore, the following risk confounders were included for comparisons: age, high sensitive C-reactive protein, homocysteine, total cholesterol, triglyceride, high-density lipoprotein, low-density lipoprotein, creatinine, vitamin B12, folate, and hemoglobin-A1C [47].

\section{Image acquisition}

MR images were acquired using a 3.0 T MRI scanner (Excite, GE Medical Systems, Milwaukee, WI, USA). Structural images were acquired for SCN constructions using the following protocols: a T1-weighted, inversionrecovery-prepared, three-dimensional, gradient-recalled acquisition in a steady-state sequence with a repetition time/echo time/inversion time of $8600 \mathrm{~ms} / \mathrm{minimal} /$ $450 \mathrm{~ms}$, a $256 \times 256 \mathrm{~mm}$ field of view, and a $1-\mathrm{mm}$ slice sagittal thickness with a resolution of $0.5 \times 0.5 \times 1 \mathrm{~mm} 3$.

The diffusion-tensor imaging was acquired using the following parameters: repetition time/echo time/flip angle $=9600 \mathrm{~ms} / 62.7 \mathrm{~ms} / 90^{\circ}$, a $192 \times 192 \mathrm{~mm}$ field of view, a $128 \times 128$ matrix and a $4-\mathrm{mm}$ axial slice thickness. For whole brain coverage, 40 contiguous axial slices were obtained. The diffusion-weighting gradients were applied in 61 non-collinear directions, optimised by the static electron-repulsion model. The $b$ value used was $1000 \mathrm{~s} / \mathrm{mm} 2$. One reference image was acquired using the same imaging parameters but without diffusion weighting.

\section{Data analysis for neuroimaging biomarkers SCN analysis}

Image preprocessing and statistical analysis were performed using SPM8 (SPM8, Wellcome Trust Centre of Cognitive Neurology, University College London, UK, http://www.fil.ion.ucl.ac.uk/spm/). The T1 images were reoriented, realigned, and normalized using the standard Montreal Neurological Institute (MNI) space. The images were then segmented into GM and WM. Related tissue segments were used to create a custom template using the diffeomorphic anatomical registration using exponentiated lie algebra (DARTEL) approach that represented one of the highest ranking registration methods in patients with $\mathrm{AD}$ [48]. The modulated and warped images were then smoothed using a Gaussian kernel of $8 \mathrm{~mm}$ full width at half maximum.

To investigate the SCNs, four regions of interest (ROIs), representing seeds, were selected from the 135 
preprocessed images. These following seed ROIs that anchor the DMN medial temporal subsystem (right entorhinal cortex [coordinates: 25,-9,-28]) [49], DMN midline core subsystem (left posterior cingulate cortex [PCC; coordinates: -2,-36, 35]) [50, 51], SN (right frontoinsular cortex [coordinates: 38, 26,-10]), and ECN (right dorsolateral prefrontal cortex [coordinates: 44, 36, 20]) [31] were selected (Fig. 1a). The laterality was based on the original report of the seeds. As the pathology or functional connectivity in typical patients with $\mathrm{AD}$ is distributed symmetrically, we did not perform a contralateral seed analysis in this study.

From the modified GM images, the GM volumes of a $4-\mathrm{mm}$ radius sphere around the seed ROI coordinates were also calculated, followed by four separate correlation analyses using the extracted GM volumes as the covariates of interest. The two genotype groups were modeled separately. For each genotype group, specific contrasts were set to identify voxels that showed positive correlations for each seed ROI, forming the SCN. The results reflected the SCNs of each ROI and the threshold was set at $p<0.01$, corrected for false discovery rate (FDR) with a cluster size $>100$ voxels.
In addition, to investigate how genetic variance may interfere with SCN clusters, voxels showing significant differences in the regression slopes in each seed-peak cluster correlations were compared, pointing to possible interactions between $\mathrm{TT}>\mathrm{C}$-carrier or $\mathrm{TT}<\mathrm{C}$-carrier based on the dosage-related IL-1 beta protein expression [13]. Specific $t$ contrasts were established to map the voxels that expressed significant between-group associations. The threshold for the resulting statistical parametric maps was set at $p<0.001$ (uncorrected) with a cluster size $>100$ voxels. For the peak clusters showing significant between-group differences, a 4-mm radius sphere was placed on the peak voxel, and the GM volumes were calculated for regression analysis. To evaluate the clinical significance of the seed or identified peak voxel, we used a linear regression model with the cognitive test scores serving as the dependent variable. The threshold was set at $p<0.05$ with multiple corrections.

\section{WM analysis}

The fractional anisotropy (FA) maps were obtained using the functional MRI of the brain software library (FSL) version 4.0.1 package (http://www.fmrib.ox.ac.uk). A direct comparison of two genotype groups of the diffusion

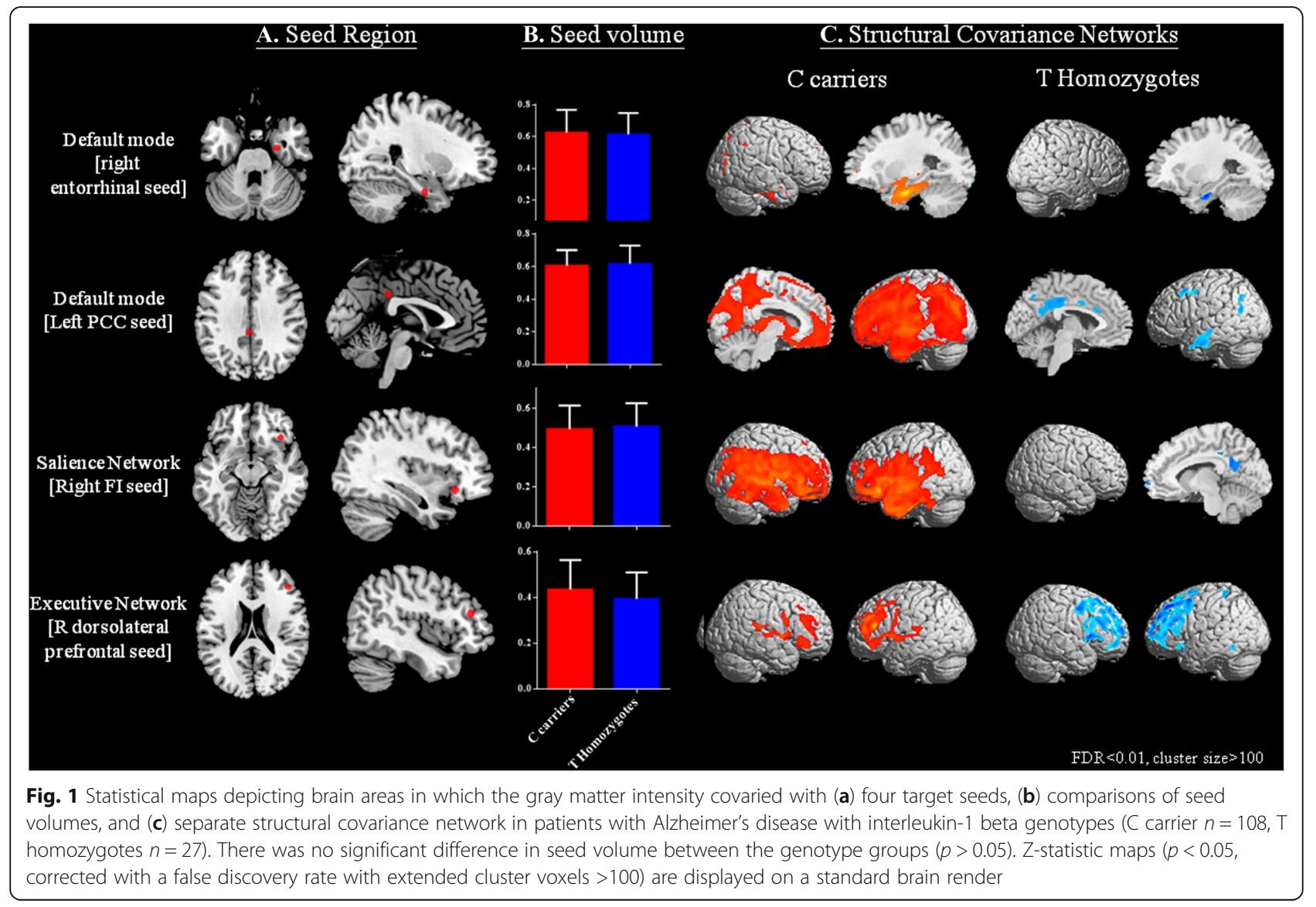


indices used permutation-based, non-parametric inference for the cluster size [52] and Randomise 2.0 software. A restrictive statistical threshold was used (the thresholdfree, cluster-enhancement threshold with $p<0.05$, corrected for multiple comparisons). To provide the between-group quantitative analysis, the WM parcellation algorithm [53] and calculation of 11 major bundles were performed. The FA from the each association bundle was extracted for group-interaction analysis or correlations with neurobehavior scores.

\section{Statistical analysis}

Clinical and laboratory data were expressed as mean \pm standard deviation. The student's $t$ test was used to compare levels of cerebrovascular risk biomarkers or continuous variables of the $\mathrm{C}$-carriers and $\mathrm{T}$ homozygotes. All statistical analyses were conducted using SPSS software (SPSS version 13 for Windows ${ }^{\circ}$, SPSS Inc., Chicago, IL). Pearson correlation adjusted for possible confounders were perfomed to assess the associations between continuous variables. Statistical significance was set at $p<0.05$.

\section{Results}

\section{Demographic data, cognitive data, and NPI}

The genotype distribution was in Hardy-Weinberg equilibrium $\left(\chi^{2}=0.28, p=0.6\right)$ and the demographic characteristics, neuropsychiatric test or cerebrovascular risk biomarker results of the two genotype groups are shown in Table 1. The clinical dementia rating scores and genotype groups distributions were not significant (E4 genotype, $\chi^{2}=0.971, p=0.262$; IL-1 beta genotype, $\chi^{2}=2.682$, $p=0.615)$.

\section{Patterns of SCN and genetic variants}

A direct comparison between the GM volume of Ccarriers or T homozygotes using voxel-based morphometry [54] showed no significant volumetric differences (with the threshold set at $p<0.05$, corrected for a FDR with a cluster size $>100$ voxels).

According to the genotype classification (C-carriers and TT-carriers) and four seeds (Fig. 1a), there were no significant differences in the GM volumes of each seed (Fig. 1b). The SCN patterns and clusters for each genotype are shown in Fig. 1c and Additional file 1: Table S1-S8.

\section{Relationships between seed region volumes and cognitive scores}

We first explored whether each seed region volume was correlated with the cognitive test scores in each group, adjusted for years of education (Table 2). The posterior cingulate, frontoinsular seed volume correlated variably with cognitive test scores in both genotypes, while the dorsolateral prefrontal seed showed significance only in the TT group.
Table 1 Demographical characteristics and neuropsychiatric tests in the interleukin-1 beta C-carrier and T-carriers in 135 cases

\begin{tabular}{|c|c|c|c|}
\hline Group & $\begin{array}{l}\text { C-carrier } \\
(n=108)\end{array}$ & $\begin{array}{l}\text { TT-carriers } \\
(n=27)\end{array}$ & $p$ value \\
\hline Age & $71.7(14.2)$ & $72.6(7.4)$ & 0.77 \\
\hline Education (year) & $6.9(4.7)$ & $9.3(4.8)$ & 0.02 \\
\hline $\begin{array}{l}\text { Apolipoprotein E4 carrier } \\
\text { (positive case, \%) }\end{array}$ & $42.6 \%$ & $48.1 \%$ & 0.67 \\
\hline Sex (male/female) & $56 / 52$ & $14 / 13$ & 1 \\
\hline Mini-Mental State Examination & $20.2(6.2)$ & $20.6(7.7)$ & 0.82 \\
\hline CASI total scores & $67.8(20.2)$ & $68.3(25.1)$ & 0.89 \\
\hline CASI executive function test scores & 25.3(7.9) & $25.2(10.1)$ & 0.97 \\
\hline \multicolumn{4}{|l|}{ CASI subdomains } \\
\hline Short term memory & $5.5(3.8)$ & $5.4(3.8)$ & 0.90 \\
\hline Orientation & $12.8(5.1)$ & $12.9(6.0)$ & 0.88 \\
\hline Long term memory & $8.3(2.4)$ & $8.4(2.7)$ & 0.90 \\
\hline Language & $8.2(2.1)$ & $8.1(2.8)$ & 0.83 \\
\hline Drawing & $7.8(2.8)$ & $8.4(2.6)$ & 0.37 \\
\hline Attention & $6.3(1.4)$ & $6.3(1.6)$ & 0.98 \\
\hline Verbal fluency & $5.2(2.5)$ & $5.3(3.7)$ & 0.86 \\
\hline Abstract thinking & $8.2(2.8)$ & $7.9(3.2)$ & 0.64 \\
\hline Mental manipulation & $5.6(3.2)$ & $5.7(3.4)$ & 0.92 \\
\hline \multicolumn{4}{|l|}{ Cerebrovascular risk biomarkers } \\
\hline $\begin{array}{l}\text { High sensitive } C \text { reactive } \\
\text { protein }(\mathrm{mg} / \mathrm{L})\end{array}$ & $2.8(4.9)$ & $2.4(5.2)$ & 0.68 \\
\hline Homocysteine (umol/L) & $12.9(4.3)$ & $11.5(4.7)$ & 0.14 \\
\hline Hemoglobin-A1C (\%) & $6.1(1.0)$ & $6.2(1.7)$ & 0.74 \\
\hline Creatinine (mg/dl) & $0.9(0.4)$ & $0.9(0.2)$ & 0.52 \\
\hline High-density lipoprotein (mg/dl) & $57.1(17.0)$ & $61.0(16.6)$ & 0.29 \\
\hline Low-density lipoprotein (mg/dl) & $106.2(38.1)$ & $97.4(28.6)$ & 0.27 \\
\hline Total cholesterol (mg/dl) & $188.5(40.8)$ & $180.6(36.0)$ & 0.36 \\
\hline Triglyceride (mg/dl) & $120.7(62.0)$ & $110.7(55.0)$ & 0.44 \\
\hline Vitamin B12 (pg/dl) & $589.1(315.7)$ & $687.2(428.1)$ & 0.19 \\
\hline Folate (ng/dl) & $12.0(5.6)$ & $12.8(5.4)$ & 0.52 \\
\hline
\end{tabular}

Data are presented as mean (standard deviation) or number (percentage (\%)) Attention, verbal fluency, abstract thinking, and mental manipulation sub-domain scores of the CASI were added to assess executive function

APOE4 carriers were defined as the presence of one or two APOE4 alleles CASI Cognitive Ability Screening Instrument

\section{Peak clusters showing significant interactions between genotype groups}

For each seed, we further explored the genotypic interactions with regards to the topography showing differences in structural covariance strength between seed and peak clusters (Fig. 2; Table 3).

The middle cingulum that anchored to the entorhinal seed was the only significant cluster showing Ccarriers $>\mathrm{TT}$ in covariance strength (Fig. 2a). In 
Table 2 Correlation matrix between cognitive test scores with seed volume

\begin{tabular}{|c|c|c|c|c|c|c|c|c|}
\hline \multirow{2}{*}{$\begin{array}{l}\text { Seed region } \\
\text { MNI coordinates } \\
\text { IL-1 beta genotypes }\end{array}$} & \multicolumn{2}{|c|}{$\begin{array}{l}\text { R entorhinal } \\
(25,-9,-28) \\
\end{array}$} & \multicolumn{2}{|c|}{$\begin{array}{l}\text { L posterior cingulate } \\
(-2,-36,35)\end{array}$} & \multicolumn{2}{|c|}{$\begin{array}{l}\text { R frontoinsular } \\
(38,26,-10)\end{array}$} & \multicolumn{2}{|c|}{$\begin{array}{l}\text { R dorsolateral prefrontal } \\
(44,36,20)\end{array}$} \\
\hline & C-carrier & $\pi$ & C-carrier & $\pi$ & C-carrier & $\pi$ & C-carrier & $\pi$ \\
\hline MMSE & 0.189 & -0.122 & $0.324^{* *}$ & $0.451^{*}$ & $0.355^{* *}$ & $0.464^{*}$ & -0.039 & $0.489^{*}$ \\
\hline CASI total scores & 0.140 & -0.105 & $0.314^{* *}$ & $0.391^{*}$ & $0.286^{* *}$ & $0.393^{*}$ & -0.027 & $0.530^{* *}$ \\
\hline CASI EFT scores & 0.109 & -0.158 & $0.294^{* *}$ & 0.344 & $0.219^{*}$ & $0.407^{*}$ & 0.000 & $0.510^{* *}$ \\
\hline \multicolumn{9}{|l|}{ CASI Subdomains } \\
\hline Short Term Memory & 0.085 & -0.012 & $0.308^{* *}$ & 0.275 & $0.335^{* *}$ & $0.475^{*}$ & 0.064 & $0.401^{*}$ \\
\hline Orientation & 0.136 & -0.133 & $0.308^{* *}$ & 0.376 & $0.342^{* *}$ & 0.362 & -0.044 & $0.457^{*}$ \\
\hline Long Term Memory & 0.188 & 0.074 & 0.172 & 0.351 & 0.148 & 0.131 & -0.041 & $0.485^{*}$ \\
\hline Language & 0.155 & -0.101 & $0.290^{* *}$ & $0.394^{*}$ & $0.235^{* *}$ & 0.255 & -0.057 & $0.484^{*}$ \\
\hline Drawing & 0.045 & -0.040 & 0.058 & $0.389^{*}$ & 0.054 & 0.281 & -0.078 & $0.472^{*}$ \\
\hline Attention & -0.013 & -0.174 & 0.200 & 0.376 & $0.246^{* *}$ & $0.421^{*}$ & 0.077 & 0.511 \\
\hline Verbal fluency & 0.083 & 0.050 & $0.272^{* *}$ & $0.406^{*}$ & 0.186 & $0.455^{*}$ & -0.001 & 0.349 \\
\hline Abstract thinking & $0.288^{* *}$ & -0.298 & 0.174 & 0.291 & $0.200^{* *}$ & 0.141 & 0.030 & $0.478^{*}$ \\
\hline Mental manipulation & -0.018 & -0.028 & $0.285^{* *}$ & 0.159 & 0.074 & $0.424^{*}$ & -0.091 & 0.367 \\
\hline
\end{tabular}

Numbers indicate Pearson correlation coefficients, ${ }^{*} p<0.05 ;{ }^{* *} p<0.01$

MMSE Mini-Mental State Examination, EFT executive function test, $R$ right, $L$ left, $I L-1$ interleukin-1, CASI Cognitive Abilities Screening Instrument, MNI Montreal Neurological Institute

contrast, there were two clusters that anchored to the right frontoinsular seed (Fig. 2b) and four clusters that anchored to the right dorsolateral prefrontal cortex seed (Fig. 2c) showing TT $>$ C-carriers in covariance strength. Meanwhile, direct comparisons of the peak clusters volume between two genotype groups showed no significant differences (Fig. 2d).

\section{Clinical significance of peak clusters showing genotype differences}

The clinical significance of the aforementioned seven peak clusters showing genotype interactions was evaluated by partial correlation analysis with cognitive tests (Table 4). For right cingulum volume, the correlation analysis with cognitive test scores showed significance

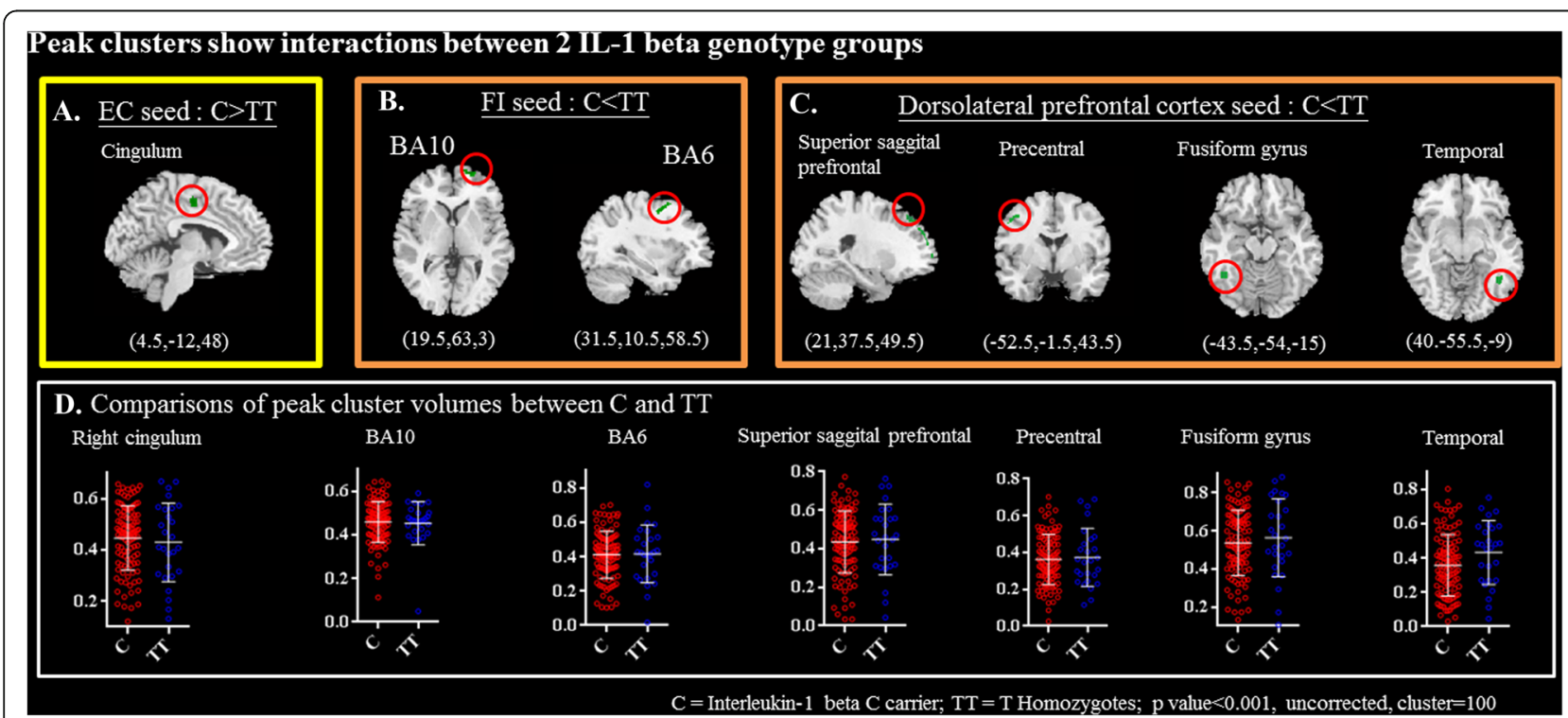

Fig. 2 Peak clusters showing significant interactions of $(\mathbf{a})$ C-carriers $(=C)>$ T homozygotes from the entorhinal seed, (b) C-carriers $<$ T homozygotes from the frontoinsular (FI) seed, or (c) C-carriers $<$ T homozygotes from the dorsolateral prefrontal seed. $(x, y, z)=$ Montreal Neurological Institute coordinates. (d) peak cluster volume comparisons (displayed as mean and standard deviation) showed no significant differences. Threshold set as $p<0.05$ 
Table 3 Connectivity interactions of interleukin-1 beta genotypes with pre-defined seed

\begin{tabular}{|c|c|c|c|c|c|c|c|c|}
\hline \multirow[t]{2}{*}{ Seed } & \multirow[t]{2}{*}{ Peak regions } & & \multicolumn{3}{|c|}{ Stereotaxic coordinates } & \multirow[t]{2}{*}{ Extent } & \multirow[t]{2}{*}{ MaxT } & \multirow[t]{2}{*}{$p$ value } \\
\hline & & & $x$ & $y$ & $z$ & & & \\
\hline \multicolumn{9}{|l|}{ C-carrier $>\pi$} \\
\hline Entorhinal seed & Middle cingulum & $\mathrm{R}$ & 5 & -12 & 48 & 118 & 3.81 & 0.0001 \\
\hline PCC seed & N.A & & & & & & & \\
\hline Frontoinsular seed & N.A & & & & & & & \\
\hline Dorsolateral prefrontal & N.A & & & & & & & \\
\hline \multicolumn{9}{|l|}{ C-carrier $<\pi$} \\
\hline Entorhinal seed & N.A & & & & & & & \\
\hline PCC seed & N.A & & & & & & & \\
\hline \multirow[t]{2}{*}{ Frontoinsular seed } & BA 10 & $\mathrm{R}$ & 19.5 & 63 & 3.0 & 196 & 4.51 & 0.0001 \\
\hline & Middle frontal & $\mathrm{R}$ & 31.5 & 10.5 & 58.5 & 243 & 3.47 & 0.0001 \\
\hline \multirow[t]{4}{*}{ Dorsolateral prefrontal } & Superior frontal & $\mathrm{R}$ & 21 & 37.5 & 49.5 & 671 & 5.09 & 0.0001 \\
\hline & Precentral & L & -52.5 & -1.5 & -43.5 & 214 & 3.58 & 0.0001 \\
\hline & Fusiform & L & -43.5 & -54 & -15 & 123 & 4.17 & 0.0001 \\
\hline & Inferior temporal & $\mathrm{R}$ & 40.5 & -55.5 & -9 & 119 & 4.03 & 0.0001 \\
\hline
\end{tabular}

Peak regions are within the main cluster

Max $\mathrm{T}$ is the maximum $\mathrm{T}$ statistic for each local maximum. $p<0.001$ with cluster size $=100$

$N$.A not available, PCC Posterior cingulate cortex, $B A$ Brodmann area, $R$ right, $L$ left

only in the C-carriers. For the six peak clusters showing $\mathrm{TT}>\mathrm{C}$-carriers in covariance strength, the frontoinsular seed- BA10 or -BA6 and dorsolateral-right temporal cluster showed significant correlations with cognitive tests in TT genotype. For C-carriers, the fusiform gyrus showed significant correlation with cognitive tests.

\section{No differences of WM integrities between two genotype groups}

For major WM tract FA, the differences between the two genotype groups and correlations with cognitive tests are shown in Table 5. The correlation between fiber bundle FA and cognitive tests were significant in both groups but there were no statistic differences between the two genotype groups.

\section{Discussion}

This study provides data on the network-specific genotype influence of IL-1 beta in the early stages of AD. There were three main findings. First, the seed-based SCN pattern validated the hypothesis that IL-1 beta C$511 \mathrm{~T}$ polymorphism targets different functional networks in patients with $\mathrm{AD}$, of which interactions between $\mathrm{C}$-carriers and $\mathrm{T}$ homozygotes differed in covariance strength. The increased covariance strength between the frontoinsular-BA10, frontoinsular-BA6, and dorsolateral-temporal axis in TT homozygotes suggest increased influences involving the anterior prefrontal-related degenerative scaffold by this genotype. In contrast, the entorhinal-cingulum connections were increased in the C-carriers. Second, IL-1 beta C-511 T functional polymorphism exerts no significant effects on the preselected cerebrovascular risk biomarkers, seed, or peak cluster volumes. Finally, the C-511 T genetic effect may interfere with the SCN network independent of the WMHs, as no differences were found between the two genotype groups in diffusion parameters.

\section{IL-1 beta genotypes and AD diagnosis}

The impact of IL-1 beta C-511 $\mathrm{T}$ polymorphism on amyloid beta immunoreactivity in the brains of patients with $\mathrm{AD}$ [55] or amyloid beta levels in the cerebral spinal fluid of patients with AD [56] suggest the important role of this polymorphism in modulating the pathology of $\mathrm{AD}$, although findings regarding C-511 T polymorphism on the susceptibility to AD or the effect on $\mathrm{AD}$ onset age have been inconsistent [14, 55-58]. IL1 beta exerts a myriad of effects in the brain and, in particular, plays a significant role in hippocampal synaptic function, which is implicated in the AD pathogenesis [9]. Although an increased IL-1 beta expression has been reported in Taiwan Chinese TT-carriers [14] which is thought to modulate hippocampal function, we did not find such relationships between the -511 TT polymorphism and entorhinal seed volume and cognitive outcomes. In contrast, the significant correlations between cognitive test scores and cingulum volume (i.e., entorhinal-interconnect peak cluster) in the $-511 \mathrm{C}$ carriers may support the selective IL-1 beta genetic modulation in the entorhinal anchored network of $\mathrm{AD}$ 
Table 4 Correlation matrix between cognitive test scores with peak clusters volume

\begin{tabular}{|c|c|c|c|c|c|c|c|}
\hline \multirow{3}{*}{$\begin{array}{l}\text { Covariance strength relationship } \\
\text { Seed region } \\
\text { Peak clusters }\end{array}$} & \multirow{3}{*}{$\begin{array}{l}C>\pi \\
R \text { entorhinal } \\
R \text { cingulum }\end{array}$} & \multicolumn{6}{|l|}{$C<\pi$} \\
\hline & & \multicolumn{2}{|c|}{$\mathrm{R}$ frontoinsular seed } & \multicolumn{4}{|l|}{ R dorsolateral seed } \\
\hline & & BA10 & BA6 & $\begin{array}{l}\text { R superior sagittal } \\
\text { prefrontal }\end{array}$ & L precentral & L fusiform gyrus & R temporal \\
\hline Cognitive tests & \multicolumn{7}{|c|}{ IL-1 beta genotype :-511 C-carriers } \\
\hline MMSE & $0.24^{*}$ & 0.07 & 0.15 & 0.16 & $0.24^{*}$ & 0.17 & 0.06 \\
\hline CASI total scores & $0.26^{* *}$ & 0.09 & $0.19^{*}$ & 0.17 & $0.28^{* *}$ & 0.19 & 0.05 \\
\hline CASI EFT scores & $0.21^{*}$ & 0.12 & 0.16 & 0.13 & $0.25^{* *}$ & $0.19^{*}$ & 0.07 \\
\hline \multicolumn{8}{|l|}{ CASI subdomains } \\
\hline Short-term memory & $0.21^{*}$ & 0.04 & 0.08 & 0.12 & $0.26^{* *}$ & 0.07 & 0.05 \\
\hline Orientation & $0.22^{*}$ & -0.03 & 0.15 & 0.09 & $0.24^{*}$ & 0.16 & 0.08 \\
\hline Long-term memory & $0.31^{* *}$ & 0.05 & 0.16 & 0.18 & $0.25^{* *}$ & 0.04 & 0.15 \\
\hline Language & 0.16 & 0.04 & 0.16 & $0.30^{* *}$ & 0.25 & 0.09 & -0.06 \\
\hline Drawing & 0.14 & 0.16 & 0.19 & 0.11 & 0.05 & $0.29^{* *}$ & -0.06 \\
\hline Attention & 0.17 & 0.05 & 0.17 & 0.06 & $0.30^{* *}$ & 0.01 & -0.07 \\
\hline Verbal fluency & $0.23^{*}$ & 0.04 & 0.04 & 0.18 & $0.23^{*}$ & 0.18 & 0.03 \\
\hline Abstract thinking & $0.20^{*}$ & 0.11 & 0.12 & 0.09 & 0.12 & $0.25^{*}$ & 0.07 \\
\hline Mental manipulation & 0.07 & 0.14 & 0.14 & 0.12 & 0.17 & 0.17 & 0.15 \\
\hline Cognitive tests & \multicolumn{7}{|c|}{ IL-1 beta genotype :-511 Tा } \\
\hline MMSE & 0.12 & $0.43^{*}$ & $0.39^{*}$ & 0.36 & 0.30 & $0.40^{*}$ & $0.48^{*}$ \\
\hline CASI total scores & 0.14 & $0.47^{*}$ & $0.44^{*}$ & $0.48^{*}$ & 0.34 & 0.35 & $0.56^{* *}$ \\
\hline CASI EFT scores & 0.21 & $0.44^{*}$ & $0.39^{*}$ & $0.39^{*}$ & $0.40^{*}$ & 0.35 & $0.60^{* *}$ \\
\hline \multicolumn{8}{|l|}{ CASI Subdomains } \\
\hline Short Term Memory & -0.03 & 0.34 & 0.19 & 0.38 & 0.02 & 0.37 & 0.22 \\
\hline Orientation & 0.16 & $0.43^{*}$ & 0.39 & $0.42^{*}$ & 0.24 & 0.30 & $0.46^{*}$ \\
\hline Long Term Memory & 0.02 & 0.36 & 0.49 & $0.54^{* *}$ & $0.39^{*}$ & 0.22 & $0.56^{* *}$ \\
\hline Language & 0.11 & 0.38 & 0.51 & $0.48^{*}$ & $0.43^{*}$ & 0.30 & $0.60^{* *}$ \\
\hline Drawing & 0.09 & $0.55^{* *}$ & 0.48 & $0.54^{* *}$ & 0.31 & 0.26 & $0.51^{* *}$ \\
\hline Attention & 0.06 & 0.32 & 0.27 & 0.35 & 0.39 & 0.33 & $0.57^{* *}$ \\
\hline Verbal fluency & 0.30 & $0.69^{* *}$ & $0.46^{*}$ & 0.27 & 0.29 & 0.23 & $0.39^{*}$ \\
\hline Abstract thinking & 0.26 & 0.37 & $0.40^{*}$ & 0.39 & $0.41^{*}$ & 0.19 & $0.56^{* *}$ \\
\hline Mental manipulation & 0.01 & 0.29 & 0.30 & 0.29 & 0.28 & $0.43^{*}$ & $0.47^{*}$ \\
\hline
\end{tabular}

Numbers indicate Pearson correlation coefficients between peak cluster volume and test scores, ${ }^{*} p<0.05 ;{ }^{* *} p<0.01$

MMSE Mini-Mental State Examination, EFT executive function test, $R$ right, $L$ left, IL-1 interleukin-1, CASI Cognitive Abilities Screening Instrument, BA Brodmann area, C IL-1 beta C-carrier, $\pi \mathrm{T}$ Homozygotes

patients. In contrast, no association was reported between the IL-1 -511 TT polymorphism and AD in Hong Kong [59] or China [60] Han Chinese. This discrepancy may partially reflect differences in ethnicity among Han Chinese [61].

While the DMN in patients with AD has been demonstrated to show reduced connectivity compared with controls, enhanced resting-state functional connectivity of the SN [62] or ECN [32, 33] has also been found in AD patients. The increase in network connectivity in $\mathrm{AD}$ has been hypothesized to reflect a compensatory mechanism for weakened posterior hubs [63] and to participate in functions such as sustained attention, working memory, response selection, or suppression [31]. As such, changes in structural covariance strength in the IL-1 beta C-511 $\mathrm{T}$ polymorphism may infer the capacity of this polymorphism to modulate symptoms in patients with AD. As increased covariance strength indicates stronger interconnections between seed and peak clusters, we speculate the -511 TT variant may potentially be a more vulnerable genotype group in this context. Once the compensatory regions located in the anterior brain axis were involved by pathology, the specific involvement of the 
Table 5 Significant relationships between major white matter tracts integrity and interleukin-1 beta genotype groups or cognitive test scores

\begin{tabular}{|c|c|c|c|c|c|c|c|c|}
\hline \multirow[b]{2}{*}{ Major white matter tract fractional anisotropy } & \multicolumn{2}{|c|}{ Fractional anisotropy } & \multicolumn{2}{|l|}{ MMSE } & \multicolumn{2}{|c|}{ CASI total scores } & \multicolumn{2}{|l|}{ CASI EFT } \\
\hline & C-carrier & $\pi$ & C-carrier & $\pi$ & C-carrier & $\pi$ & C-carrier & $\pi$ \\
\hline Forceps major & $0.47(0.04)$ & $0.48(0.05)$ & $0.25^{*}$ & $0.40^{*}$ & $0.29 * *$ & 0.34 & $0.35^{* *}$ & $0.40^{*}$ \\
\hline Forceps minor & $0.35(0.03)$ & $0.35(0.03)$ & $0.26^{*}$ & $0.48^{*}$ & $0.28^{* *}$ & $0.44^{*}$ & $0.34^{* *}$ & $0.52^{*}$ \\
\hline Anterior thalamic radiation & $0.60(0.06)$ & $0.61(0.06)$ & $0.22^{*}$ & $0.48^{*}$ & $0.24^{*}$ & $0.42^{*}$ & $0.30^{* *}$ & $0.48^{*}$ \\
\hline Corticospinal tract & 0.99(0.06) & 0.99(0.06) & $0.37^{* *}$ & 0.10 & $0.39^{* *}$ & 0.07 & $0.44^{* *}$ & 0.17 \\
\hline Cingulum & $0.68(0.06)$ & $0.68(0.07)$ & $0.29^{* *}$ & $0.41^{*}$ & $0.32^{* *}$ & 0.36 & $0.32^{* *}$ & $0.43^{*}$ \\
\hline Cingulum (hippocampus) & $0.58(0.07)$ & $0.59(0.06)$ & $0.41^{* *}$ & 0.18 & $0.45^{* *}$ & 0.16 & $0.38^{* *}$ & 0.17 \\
\hline Inferior fronto-occipital fasciculus & $0.74(0.05)$ & $0.74(0.06)$ & $0.22^{*}$ & 0.29 & $0.26^{*}$ & 0.24 & $0.34^{* *}$ & 0.29 \\
\hline Inferior longitudinal fasciculus & $0.74(0.05)$ & $0.75(0.05)$ & $0.26^{*}$ & 0.31 & $0.30^{* *}$ & 0.29 & $0.37^{* *}$ & 0.32 \\
\hline Superior longitudinal fasciculus & $0.63(0.05)$ & $0.63(0.06)$ & $0.20^{*}$ & 0.24 & $0.23^{*}$ & 0.22 & $0.27^{* *}$ & 0.29 \\
\hline Uncinate fasciculus & $0.68(0.05)$ & $0.68(0.04)$ & $0.26^{*}$ & 0.20 & $0.28^{* *}$ & 0.13 & $0.30^{* *}$ & 0.17 \\
\hline Superior longitudinal fasciculus (temporal part) & $0.90(0.08)$ & $0.89(0.09)$ & 0.14 & 0.26 & 0.18 & 0.27 & $0.24^{*}$ & 0.32 \\
\hline
\end{tabular}

Data of Fractional Anisotropy represent mean (standard deviation), MMSE Mini-Mental State Examination scores, CASI Cognitive Ability Screening Instrument, EFT executive function test, EFT Sum of attention, verbal fluency, abstract thinking, and mental manipulation sub-domain scores of the CASI, $T T$ T homozygotes Numbers indicate mean and standard deviation or Pearson correlation coefficient; ${ }^{*} p<0.05{ }^{* *} p<0.01$

SN and ECN in the TT group may accelerate the degeneration process.

\section{IL-1 beta genotypes and brain network analysis}

The mechanism by which IL-1 beta C-511 T polymorphism affect the brain networks in patients with $\mathrm{AD}$ has yet to be fully established. The higher IL-1 beta gene expression during long-term potentiation suggests its role in synaptic function [15]. In patients with mild to moderate stage $\mathrm{AD}$, carriers of the $-511 \mathrm{C}$ allele have been shown to have a reduced inflammatory response, and this has been proposed to allow for better cognitive improvements on a ketone body based treatment [64]. Studies of other IL-1 beta polymorphisms have also suggested the anti-correlated relationships between the expression of IL-1 beta and cognitive performance [65]. Functional connectivity analysis in normal elderly has shown that the IL-1 beta -511 TT carriers have reduced connectivity of the anterior mid-cingulate-prefrontalstriate networks [66], pointing to the role of this functional polymorphism and the anterior brain network.

Our analysis provides evidence that GM network alterations may be considered as the endophenotype of the IL-1 beta C-511 T polymorphism that predicts the cognitive outcomes. Although we purposed that increased structural covariance strength within functional network may lead to detrimental effects in patients with $\mathrm{AD}$, whether the genetic effects by our reports fully address the hippocampal IL-1 beta expression still left unexplored. Data on IL-1 beta genotypes and postmortem IL-1 beta level examinations are needed to elucidate the consequences. In line with our findings, several neuroimaging studies have also demonstrated the detrimental effects of IL-1 beta -511 T allele on fronto-temporal GM $[67,68]$, left dorsolateral prefrontal cortex [68-70], or parahippocampus [71] in various brain disorders.

Increased structural covariance between the cingulum peak cluster and entorhinal seed was found in the $C$ carriers compared with TT homozygotes. Adjusted for educational years, this covariance also determines cognitive test scores in the $C$ carriers, suggesting the unique covariance strength relationship in terms of spatial distribution in AD. Current research criteria of AD [40] do not include the influence of genomic data; however, recent results from studies on neuronal exosomes and nanosomes [72-74] support the importance of metabolic and inflammatory abnormalities in predicting the prodromal phase. Since metabolic and inflammatory functions are greatly under genetic control, this may be productive if genetic profiling is taken into consideration in the diagnosis of patients with cognitive deficits.

\section{IL-1 beta genotypes and cognition}

There have been many IL-1 beta genetic association studies on individuals without dementia during the cognitive aging stages. A cross-sectional study reported a significant relationship between C-511 $\mathrm{T}$ polymorphism and episodic memory, with a better performance in the $\mathrm{C}$ homozygous than in the CT/TT group [75]. As the authors [75] did not find any association between this polymorphism and attention, processing or motor function, they suggested that the effect of this IL-1 beta polymorphism on cognition may be domain-specific (i.e., memory-specific). In accordance with their findings, two other studies on elderly males [45] and elderly females [76] showed that $-511 \mathrm{C}$-carriers had higher scores in 
general or in selective cognitive tests compared to the $\mathrm{T}$ homozygotes. After adjusting for years of education, our correlation results suggested parallel relationships between seed and peak cluster volumes in relation to cognitive tests scores in the genotype groups. As the crosssectional cognitive test design may have resulted in population selections bias, data on cross-sectional models may not fully address whether IL-1 beta C-511 T polymorphisms mediate domain-specific cognitive deficits or whether they are more generalized $[45,77,78]$. A longitudinal follow-up study may increase the accuracy of genotypes and involved cognitive domains. In contrast to previous reports, our study analysis did not establish a direct C-511 T genotype effect on cognitive test scores.

\section{IL-1 beta genotypes and WMHs}

Homozygotes for the IL-1 beta $-511 \mathrm{~T}$ allele have been associated with larger WMHs than other genotypic combinations in the elderly without dementia [24]; however, we did not find such an association in AD. Nonetheless, our results show that the IL-1 beta genetic effect can be solely present in the GM network, and that this effect is independent of the modulation of WMHs. Our study only enrolls patients in the early stage and AD pathology is more localized in the GM in the early stage of $\mathrm{AD}$. Thus, the influence of IL-1 beta C-511 T polymorphism on WMHs may be stage-specific.

\section{Study limitations}

An important limitation of this study is that we did not include a control group. The enrolment of controls may help to understand whether IL-1 beta C-511 T polymorphism has similar effects on the normative brain network. Nonetheless, the aim of this study was to determine whether changes in the SCN caused by IL-1 beta genetic polymorphism in AD patients. Our results support the data from elderly healthy subjects [71] that genetic variations of IL-1 beta mediate the dorsolateral prefrontal cortex, yet the analysis of SCN patterns with changes in structural covariance strength was not available. Another potential limitation is that we reported the genetic effect between the C-carriers and TT homozygotes, and such group stratification could not explore the model of heterozygote advantage. We based this decision on the small sample size and a previously published report [13] on the IL-1 beta dosage effects. Thirdly, as clinical significance was established in four pre-defined networks, we did not test whether other networks participated in genetic modulation. The use of independent component analysis [79] or resting state functional MRI data may elucidate other potential networks and also validate the findings observed in this study. Finally, cognitive tests such as MMSE and CASI are often used as screening tests. Further studies are warranted that include an extensive battery of tests.

\section{Conclusions}

In the early stages of $\mathrm{AD}$, our analysis supports that IL-1 beta $\mathrm{C}-511 \mathrm{~T}$ polymorphism modulates the strength of the structural covariance independent of WMHs. The -511 TT homozygotes convey increased covariance patterns in anterior brain networks that may then modulate the degenerative process differently from the patterns of entorhinal-cingulum networks in C-carriers.

\section{Additional file}

Additional file 1: The peak clusters in the structural covariance network. (DOCX $39 \mathrm{~kb})$

\section{Abbreviations}

AD: Alzheimer's disease; CASI: Cognitive Abilities Screening Instrument; DARTEL: Diffeomorphic anatomical registration using exponentiated lie algebra; DMN: Default mode network; ECN: Executive control network; EFT: Executive function test; FA: Fractional anisotropy; FDR: False discovery rate; GM: Gray matter; IL-1: Interleukin-1; MMSE: Mini-Mental State Examination; MNI: Montreal Neurological Institute; PCR: Polymerase chain reaction; ROIs: Regions of interest; SCNs: Structural covariance networks; SN: Salience network; WM: White matter; WMHs: White matter hyperintensities

\section{Acknowledgements}

The authors wish to acknowledge Yu-Ting Lin and Su-Chen Liu for the experiment schedule.

\section{Funding}

This work was supported by grants CMRPG8C0571, CMRPG8D0771, and CMRPG8E0541 from Chang Gung Memorial Hospital, and 104-2314-B-182A026-MY2 from the National Science Council to CCC for MRI acquisition, genetic, and clinical data collection and analysis.

\section{Availability of data and materials}

The datasets generated during and/or analyzed during the current study are not publicly available due to the intelligence rights owned by the hospital and the authors but are available from the corresponding author on reasonable request.

\section{Authors' contributions}

CW, SJ, and ME carried out the genetic studies, participated in the sequence alignment and drafted the manuscript. SW and CC-Lee carried out the MRI acquisition, data analysis, and interpretation. MT participated in the sequence alignment. NC, SH, YT, and WC participated in the design of the study and performed the statistical analysis. SJ and CC-Chang conceived of the study, participated in its design and coordination, and helped to draft the manuscript. WN provided critical intellectual information for the revision. All authors read and approved the final manuscript.

\section{Competing interests}

The authors declare that they have no competing interests.

\section{Consent for publication}

Not applicable.

\section{Ethics approval and consent to participate}

This study was conducted in accordance with the Declaration of Helsinki and was approved by the Institutional Review Board of Chang Gung Memorial Hospital (IRB 103-9997A3). The study participants and their caregivers agreed on the participation of the study with written informed consent. 


\section{Author details}

'Department of Neurology, Cognition and Aging Center, Kaohsiung Chang Gung Memorial Hospital, Chang Gung University College of Medicine, \#123, Ta-Pei Road, Niaosung, Kaohsiung County 833, Taiwan. ${ }^{2}$ Department of Radiology, Kaohsiung Chang Gung Memorial Hospital, Chang Gung University College of Medicine, Niaosung, Kaohsiung, Taiwan. ${ }^{3}$ Psychiatric Department of Taipei Veterans General Hospital, Taipei, Taiwan. ${ }^{4}$ Psychiatric Division, School of Medicine, National Yang-Ming University, Taipei, Taiwan. ${ }^{5}$ Department of Nuclear Medicine, Cognition and Aging Center, Kaohsiung Chang Gung Memorial Hospital, Chang Gung University College of Medicine, Niaosung, Kaohsiung, Taiwan.

Received: 5 August 2016 Accepted: 4 January 2017

\section{Published online: 18 January 2017}

\section{References}

1. Dickson DW, Lee SC, Mattiace LA, Yen SH, Brosnan C. Microglia and cytokines in neurological disease, with special reference to AIDS and Alzheimer's disease. Glia. 1993;7:75-83.

2. Holmes C, Cunningham C, Zotova E, Woolford J, Dean C, Kerr S, Culliford D, Perry VH. Systemic inflammation and disease progression in Alzheimer disease. Neurology. 2009;73:768-74.

3. Nelson PT, Alafuzoff I, Bigio EH, Bouras C, Braak H, Cairns NJ, Castellani RJ, Crain BJ, Davies P, Del Tredici K, et al. Correlation of Alzheimer disease neuropathologic changes with cognitive status: a review of the literature. J Neuropathol Exp Neurol. 2012:71:362-81.

4. Wirth M, Madison CM, Rabinovici GD, Oh H, Landau SM, Jagust WJ. Alzheimer's disease neurodegenerative biomarkers are associated with decreased cognitive function but not beta-amyloid in cognitively normal older individuals. J Neurosci. 2013;33:5553-63.

5. Candore G, Bulati M, Caruso C, Castiglia L, Colonna-Romano G, Di Bona D, Duro G, Lio D, Matranga D, Pellicano M, et al. Inflammation, cytokines,

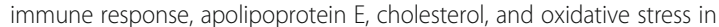
Alzheimer disease: therapeutic implications. Rejuvenation Res. 2010;13:301-13.

6. Cevenini E, Caruso C, Candore G, Capri M, Nuzzo D, Duro G, Rizzo C, Colonna-Romano G, Lio D, Di Carlo D, et al. Age-related inflammation: the contribution of different organs, tissues and systems. How to face it for therapeutic approaches. Curr Pharm Des. 2010;16:609-18.

7. Di Bona D, Scapagnini G, Candore G, Castiglia L, Colonna-Romano G, Duro G, Nuzzo D, lemolo F, Lio D, Pellicano M, et al. Immuneinflammatory responses and oxidative stress in Alzheimer's disease: therapeutic implications. Curr Pharm Des. 2010;16:684-91.

8. Vasto S, Candore G, Duro G, Lio D, Grimaldi MP, Caruso C. Alzheimer's disease and genetics of inflammation: a pharmacogenomic vision. Pharmacogenomics. 2007;8:1735-45.

9. Lynch MA. Interleukin-1 beta exerts a myriad of effects in the brain and in particular in the hippocampus: analysis of some of these actions. Vitam Horm. 2002;64:185-219.

10. Shaftel SS, Kyrkanides S, Olschowka JA, Miller JN, Johnson RE, O'Banion MK. Sustained hippocampal IL-1 beta overexpression mediates chronic neuroinflammation and ameliorates Alzheimer plaque pathology. J Clin Invest. 2007;117:1595-604.

11. Ghosh S, Wu MD, Shaftel SS, Kyrkanides S, LaFerla FM, Olschowka JA, O'Banion MK. Sustained interleukin-1beta overexpression exacerbates tau pathology despite reduced amyloid burden in an Alzheimer's mouse model. J Neurosci. 2013;33:5053-64

12. Hollegaard MV, Bidwell JL. Cytokine gene polymorphism in human disease: on-line databases, supplement 3. Genes Immun. 2006;7:269-76.

13. Pociot F, Molvig J, Wogensen L, Worsaae H, Nerup J. A Taql polymorphism in the human interleukin-1 beta (IL-1 beta) gene correlates with IL-1 beta secretion in vitro. Eur J Clin Invest. 1992;22:396-402.

14. Wang WF, Liao YC, Wu SL, Tsai FJ, Lee CC, Hua CS. Association of interleukin-I beta and receptor antagonist gene polymorphisms with late onset Alzheimer's disease in Taiwan Chinese. Eur J Neurol. 2005:12:609-13.

15. Schneider H, Pitossi F, Balschun D, Wagner A, del Rey A, Besedovsky HO. A neuromodulatory role of interleukin-1 beta in the hippocampus. Proc Natl Acad Sci U S A. 1998;95:7778-83.

16. Barrientos RM, Sprunger DB, Campeau S, Watkins LR, Rudy JW, Maier SF. BDNF mRNA expression in rat hippocampus following contextual learning is blocked by intrahippocampal IL-1beta administration. J Neuroimmunol. 2004;155:119-26.
17. Huang CW, Chang WN, Lui CC, Chen CF, Lu CH, Wang YL, Chen C, Juang YY, Lin YT, Tu MC, Chang CC. Impacts of hyper-homocysteinemia and white matter hyper-intensity in Alzheimer's disease patients with normal creatinine: an MRI-based study with longitudinal follow-up. Curr Alzheimer Res. 2010;7:527-33.

18. Tu MC, Huang CW, Chen NC, Chang WN, Lui CC, Chen CF, Chen C, Wang YL, Lin YT, Chang CC. Hyperhomocysteinemia in Alzheimer dementia patients and cognitive decline after 6 months follow-up period. Acta Neurol Taiwan. 2010;19:168-77.

19. Chang YT, Chang CC, Lin HS, Huang CW, Chang WN, Lui CC, Lee CC, Lin YT, Chen $\mathrm{CH}$, Chen NC. Montreal cognitive assessment in assessing clinical severity and white matter hyperintensity in Alzheimer's disease with normal control comparison. Acta Neurol Taiwan. 2012;21:64-73.

20. Deppe M, Duning T, Mohammadi S, Schwindt W, Kugel H, Knecht S, Ringelstein EB. Diffusion-tensor imaging at $3 \mathrm{~T}$ : detection of white matter alterations in neurological patients on the basis of normal values. Invest Radiol. 2007:42:338-45.

21. Hoth KF, Haley AP, Gunstad J, Paul RH, Poppas A, Jefferson AL, Tate DF, Ono $M$, Jerskey BA, Cohen RA. Elevated C-reactive protein is related to cognitive decline in older adults with cardiovascular disease. J Am Geriatr Soc. 2008:56:1898-903.

22. Huang CW, Chang WN, Huang SH, Lui CC, Chen NC, Chang YT, Lee CC, Chang CC, Chang AY. Impact of homocysteine on cortical perfusion and cognitive decline in mild Alzheimer's dementia. Eur J Neurol. 2013;20:1191-7.

23. Huang CW, Tsai MH, Chen NC, Chen WH, Lu YT, Lui CC, Chang YT, Chang WN, Chang AY, Chang CC. Clinical significance of circulating vascular cell adhesion molecule-1 to white matter disintegrity in Alzheimer's dementia. Thromb Haemost. 2015:114:1230-40.

24. Raz N, Yang Y, Dahle CL, Land S. Volume of white matter hyperintensities in healthy adults: contribution of age, vascular risk factors, and inflammationrelated genetic variants. Biochim Biophys Acta. 1822;2012:361-9.

25. Zhang Z, Liu LJ, Zhang C, Yu YP. Association between Interleukin-1 gene single nucleotide polymorphisms and ischemic stroke classified by TOAST criteria in the Han population of northern China. Biomed Res Int. 2013;2013:961039.

26. Dziedzic T, Slowik A, Pera J, Szczudlik A. Interleukin 1 beta polymorphism $(-511)$ and risk of stroke due to small vessel disease. Cerebrovasc Dis. 2005;20:299-303.

27. Alexander-Bloch A, Giedd JN, Bullmore E. Imaging structural co-variance between human brain regions. Nat Rev Neurosci. 2013;14:322-36.

28. Greicius MD, Srivastava G, Reiss AL, Menon V. Default-mode network activity distinguishes Alzheimer's disease from healthy aging: evidence from functional MRI. Proc Natl Acad Sci U S A. 2004:101:4637-42.

29. Greicius MD, Supekar K, Menon V, Dougherty RF. Resting-state functional connectivity reflects structural connectivity in the default mode network. Cereb Cortex. 2009;19:72-8.

30. Seeley WW, Allman JM, Carlin DA, Crawford RK, Macedo MN, Greicius MD, Dearmond SJ, Miller BL. Divergent social functioning in behavioral variant frontotemporal dementia and Alzheimer disease: reciprocal networks and neuronal evolution. Alzheimer Dis Assoc Disord. 2007;21:S50-57.

31. Seeley WW, Menon V, Schatzberg AF, Keller J, Glover GH, Kenna H, Reiss AL, Greicius MD. Dissociable intrinsic connectivity networks for salience processing and executive control. J Neurosci. 2007:27:2349-56.

32. Agosta F, Pievani M, Geroldi C, Copetti M, Frisoni GB, Filippi M. Resting state $\mathrm{fMRI}$ in Alzheimer's disease: beyond the default mode network. Neurobiol Aging. 2012;33:1564-78

33. Filippi M, Agosta F, Scola E, Canu E, Magnani G, Marcone A, Valsasina P, Caso F, Copetti M, Comi G, et al. Functional network connectivity in the behavioral variant of frontotemporal dementia. Cortex. 2013:49:2389-401.

34. Andrews-Hanna JR, Reidler JS, Sepulcre J, Poulin R, Buckner RL. Functional-anatomic fractionation of the brain's default network. Neuron. 2010:65:550-62.

35. Jack Jr CR, Lowe VJ, Weigand SD, Wiste HJ, Senjem ML, Knopman DS, Shiung MM, Gunter JL, Boeve BF, Kemp BJ, et al. Serial PIB and MRI in normal, mild cognitive impairment and Alzheimer's disease: implications for sequence of pathological events in Alzheimer's disease. Brain. 2009;132:1355-65.

36. Chhatwal JP, Schultz AP, Johnson $K$, Benzinger TL, Jack Jr C, Ances BM, Sullivan CA, Salloway SP, Ringman JM, Koeppe RA, et al. Impaired default network functional connectivity in autosomal dominant Alzheimer disease. Neurology. 2013;81:736-44 
37. Hong SB, Zalesky A, Park S, Yang YH, Park MH, Kim B, Song IC, Sohn CH, Shin MS, Kim BN, et al. COMT genotype affects brain white matter pathways in attention-deficit/hyperactivity disorder. Hum Brain Mapp. 2015;36:367-77.

38. Thompson PM, Ge T, Glahn DC, Jahanshad N, Nichols TE. Genetics of the connectome. Neuroimage. 2013;80:475-88.

39. Zeidan-Chulia F, de Oliveira BH, Salmina AB, Casanova MF, Gelain DP, Noda M, Verkhratsky A, Moreira JC. Altered expression of Alzheimer's disease-related genes in the cerebellum of autistic patients: a model for disrupted brain connectome and therapy. Cell Death Dis. 2014;5:e1250.

40. Dubois B, Feldman HH, Jacova C, Cummings JL, Dekosky ST, BarbergerGateau P, Delacourte A, Frisoni G, Fox NC, Galasko D, et al. Revising the definition of Alzheimer's disease: a new lexicon. Lancet Neurol. 2010;9:1118-27.

41. Chang CC, Kramer JH, Lin KN, Chang WN, Wang YL, Huang CW, Lin YT, Chen C, Wang PN. Validating the Chinese version of the Verbal Learning Test for screening Alzheimer's disease. J Int Neuropsychol Soc. 2010;16:244-51.

42. Rosen WG, Terry RD, Fuld PA, Katzman R, Peck A. Pathological verification of ischemic score in differentiation of dementias. Ann Neurol. 1980;7:486-8.

43. Folstein MF, Folstein SE, McHugh PR. "Mini-mental state". A practical method for grading the cognitive state of patients for the clinician. J Psychiatr Res. 1975;12:189-98.

44. Teng EL, Hasegawa K, Homma A, Imai Y, Larson E, Graves A, Sugimoto K, Yamaguchi T, Sasaki H, Chiu D, et al. The Cognitive Abilities Screening Instrument (CASI): a practical test for cross-cultural epidemiological studies of dementia. Int Psychogeriatr. 1994;6:45-58. discussion 62.

45. Tsai SJ, Hong CJ, Liu ME, Hou SJ, Yen FC, Hsieh CH, Liou YJ. Interleukin-1 beta (C-511 T) genetic polymorphism is associated with cognitive performance in elderly males without dementia. Neurobiol Aging. 2010;31:1950-5.

46. Del Bo R, Comi GP, Bresolin N, Castelli E, Conti E, Degiuli A, Ausenda CD, Scarlato $\mathrm{G}$. The apolipoprotein E epsilon4 allele causes a faster decline of cognitive performances in Down's syndrome subjects. J Neurol Sci. 1997:145:87-91.

47. Wu MK, Lu YT, Huang CW, Lin PH, Chen NC, Lui CC, Chang WN, Lee CC, Chang YT, Chen SF, Chang CC. Clinical significance of cerebrovascular biomarkers and white matter tract integrity in Alzheimer disease: clinical correlations with neurobehavioral data in cross-sectional and after 18 months follow-ups. Medicine (Baltimore). 2015;94:e1192.

48. Cuingnet R, Gerardin E, Tessieras J, Auzias G, Lehericy S, Habert MO, Chupin M, Benali H, Colliot O. Automatic classification of patients with Alzheimer's disease from structural MRI: a comparison of ten methods using the ADNI database. Neuroimage. 2011;56:766-81.

49. Bernhardt BC, Worsley KJ, Besson P, Concha L, Lerch JP, Evans AC, Bernasconi N. Mapping limbic network organization in temporal lobe epilepsy using morphometric correlations: insights on the relation between mesiotemporal connectivity and cortical atrophy. Neuroimage. 2008;42:515-24

50. Spreng RN, Turner GR. Structural covariance of the default network in healthy and pathological aging. J Neurosci. 2013;33:15226-34.

51. Zielinski BA, Anderson JS, Froehlich AL, Prigge MB, Nielsen JA, Cooperrider JR, Cariello AN, Fletcher PT, Alexander AL, Lange N, et al. scMRl reveals large-scale brain network abnormalities in autism. PLoS One. 2012;7:e49172.

52. Nichols TE, Holmes AP. Nonparametric permutation tests for functional neuroimaging: a primer with examples. Hum Brain Mapp. 2002;15:1-25.

53. Hua K, Zhang J, Wakana S, Jiang H, Li X, Reich DS, Calabresi PA, Pekar JJ, van Zijl PC, Mori S. Tract probability maps in stereotaxic spaces: analyses of white matter anatomy and tract-specific quantification. Neuroimage. 2008:39:336-47.

54. Ashburner J, Friston KJ. Voxel-based morphometry-the methods. Neuroimage. 2000;11:805-21.

55. Green EK, Harris JM, Lemmon H, Lambert JC, Chartier-Harlin MC, St Clair D, Mann DM, Iwatsubo T, Lendon CL. Are interleukin-1 gene polymorphisms risk factors or disease modifiers in AD? Neurology. 2002;58:1566-8.

56. Ehl C, Kolsch H, Ptok U, Jessen F, Schmitz S, Frahnert C, Schlosser R, Rao ML, Maier W, Heun R. Association of an interleukin-1beta gene polymorphism at position -511 with Alzheimer's disease. Int J Mol Med. 2003;11:235-8.

57. Grimaldi LM, Casadei VM, Ferri C, Veglia F, Licastro F, Annoni G, Biunno I, De Bellis G, Sorbi S, Mariani C, et al. Association of early-onset Alzheimer's disease with an interleukin-1alpha gene polymorphism. Ann Neurol. 2000;47:361-5.

58. Licastro F, Pedrini S, Ferri C, Casadei V, Govoni M, Pession A, Sciacca FL, Veglia F, Annoni G, Bonafe $M$, et al. Gene polymorphism affecting alpha1-antichymotrypsin and interleukin-1 plasma levels increases Alzheimer's disease risk. Ann Neurol. 2000;48:388-91.

59. Ma SL, Tang NL, Lam LC, Chiu HF. Lack of association of the interleukin1 beta gene polymorphism with Alzheimer's disease in a Chinese population. Dement Geriatr Cogn Disord. 2003;16:265-8.

60. Li XQ, Zhang JW, Zhang ZX, Chen D, Qu QM. Interleukin-1 gene cluster polymorphisms and risk of Alzheimer's disease in Chinese Han population. J Neural Transm (Vienna). 2004;111:1183-90.

61. Chen CH, Yang JH, Chiang CW, Hsiung CN, Wu PE, Chang LC, Chu HW, Chang J, Song IW, Yang SL, et al. Population structure of Han Chinese in the modern Taiwanese population based on 10,000 participants in the Taiwan Biobank project. Hum Mol Genet. 2016.

62. Supekar K, Menon V, Rubin D, Musen M, Greicius MD. Network analysis of intrinsic functional brain connectivity in Alzheimer's disease. PLoS Comput Biol. 2008:4:e1000100.

63. Zhou J, Greicius MD, Gennatas ED, Growdon ME, Jang JY, Rabinovici GD, Kramer JH, Weiner M, Miller BL, Seeley WW. Divergent network connectivity changes in behavioural variant frontotemporal dementia and Alzheimer's disease. Brain. 2010;133:1352-67.

64. Henderson ST, Poirier J. Pharmacogenetic analysis of the effects of polymorphisms in APOE, IDE and IL1B on a ketone body based therapeutic on cognition in mild to moderate Alzheimer's disease: a randomized, double-blind, placebo-controlled study. BMC Med Genet. 2011;12:137.

65. Benke KS, Carlson MC, Doan BQ, Walston JD, Xue QL, Reiner AP, Fried LP, Arking DE, Chakravarti A, Fallin MD. The association of genetic variants in interleukin-1 genes with cognition: findings from the cardiovascular health study. Exp Gerontol. 2011;46:1010-9.

66. Tu PC, Su TP, Huang CC, Yang AC, Yeh HL, Hong CJ, Liou YJ, Liu ME, Lin CP, Tsai SJ. Interleukin-1 beta C-511 T polymorphism modulates functional connectivity of anterior midcingulate cortex in non-demented elderly Han males. Brain Struct Funct. 2014;219:61-9.

67. Meisenzahl EM, Rujescu D, Kirner A, Giegling I, Kathmann N, Leinsinger G, Maag K, Hegerl U, Hahn K, Moller HJ. Association of an interleukin-1beta genetic polymorphism with altered brain structure in patients with schizophrenia. Am J Psychiatry. 2001;158:1316-9.

68. Papiol S, Molina V, Desco M, Rosa A, Reig S, Sanz J, Palomo T, Fananas L. Gray matter deficits in bipolar disorder are associated with genetic variability at interleukin-1 beta gene (2q13). Genes Brain Behav. 2008;7:796-801.

69. Papiol S, Molina V, Rosa A, Sanz J, Palomo T, Fananas L. Effect of interleukin1 beta gene functional polymorphism on dorsolateral prefrontal cortex activity in schizophrenic patients. Am J Med Genet B Neuropsychiatr Genet. 2007;144B:1090-3.

70. Fatjo-Vilas M, Pomarol-Clotet E, Salvador R, Monte GC, Gomar JJ, Sarro S, Ortiz-Gil J, Aguirre C, Landin-Romero R, Guerrero-Pedraza A, et al. Effect of the interleukin-1beta gene on dorsolateral prefrontal cortex function in schizophrenia: a genetic neuroimaging study. Biol Psychiatry. 2012;72:758-65.

71. Persson N, Ghisletta P, Dahle CL, Bender AR, Yang Y, Yuan P, Daugherty AM, Raz N. Regional brain shrinkage over two years: individual differences and effects of pro-inflammatory genetic polymorphisms. Neuroimage. 2014;103:334-48.

72. Fiandaca MS, Kapogiannis D, Mapstone M, Boxer A, Eitan E, Schwartz JB, Abner EL, Petersen RC, Federoff HJ, Miller BL, Goetzl EJ. Identification of preclinical Alzheimer's disease by a profile of pathogenic proteins in neurally derived blood exosomes: a case-control study. Alzheimers Dement. 2015;11:600-7. e601.

73. Goetzl EJ, Boxer A, Schwartz JB, Abner EL, Petersen RC, Miller BL, Carlson OD, Mustapic M, Kapogiannis D. Low neural exosomal levels of cellular survival factors in Alzheimer's disease. Ann Clin Transl Neurol. 2015;2:769-73.

74. Goetzl EJ, Boxer A, Schwartz JB, Abner EL, Petersen RC, Miller BL, Kapogiannis D. Altered lysosomal proteins in neural-derived plasma exosomes in preclinical Alzheimer disease. Neurology. 2015;85:40-7.

75. Baune BT, Ponath $\mathrm{G}$, Rothermundt M, Riess O, Funke H, Berger K. Association between genetic variants of IL-1 beta, IL- 6 and TNF-alpha cytokines and cognitive performance in the elderly general population of the MEMO-study. Psychoneuroendocrinology. 2008;33:68-76.

76. Sasayama D, Hori H, Teraishi T, Hattori K, Ota M, Matsuo J, Kawamoto Y, Kinoshita Y, Higuchi T, Amano N, Kunugi H. Association of interleukin-1beta genetic polymorphisms with cognitive performance in elderly females without dementia. J Hum Genet. 2011;56:613-6.

77. Lau S, Bates KA, Sohrabi HR, Rodrigues M, Martins G, Dhaliwal SS, Taddei K, Laws SM, Martins IJ, Mastaglia FL, et al. Functional effects of genetic 
polymorphism in inflammatory genes in subjective memory complainers. Neurobiol Aging. 2012;33:1054-6.

78. Marioni RE, Deary IJ, Murray GD, Fowkes FG, Price JF. Associations between polymorphisms in five inflammation-related genes and cognitive ability in older persons. Genes Brain Behav. 2010;9:348-52.

79. Beckmann CF, DeLuca M, Devlin JT, Smith SM. Investigations into restingstate connectivity using independent component analysis. Philos Trans R Soc Lond B Biol Sci. 2005;360:1001-13.

Submit your next manuscript to BioMed Central and we will help you at every step:

- We accept pre-submission inquiries

- Our selector tool helps you to find the most relevant journal

- We provide round the clock customer support

- Convenient online submission

- Thorough peer review

- Inclusion in PubMed and all major indexing services

- Maximum visibility for your research

Submit your manuscript at www.biomedcentral.com/submit 